scheme" and companies compete to create links with physicians who can recruit patients, conduct studies, lecture about new products and "provide overall credibility" to industry-sponsored research, University of Toronto law professor Trudo Lemmens states in a draft document submitted to the bioethics education program of the Royal College of Physicians and Surgeons of Canada.

\section{Costs and payment}

In academic settings, about $30 \%$ of a clinical trial budget goes to pay overhead costs, says Dr. Penny MoodyCorbett of the Faculty of Medicine at Memorial University in St. John's, Newfoundland and Labrador. She adds that the common perception that trials are a money-maker for institutions is errant. At Memorial, "they have not been a lucrative activity ... that is our experience."

Whether physicians are remunerated for time spent on clinical trials appears conditional on institution and discipline. Meyers says no extra payment goes to physicians who are on salary and working in the field of cancer. Rather, the monies are used to pay for clinical research assistants and staff, and to pay hospitals for extra tests and procedures the trial requires.

CMA guidelines say that physician compensation for trials work should be over and above their usual care for patients. Blackmer says it should also be commensurate with expenses incurred and that research subjects must be told if their doctor is receiving a fee for their participation in a trial, and "by whom the fee will be paid."

Regardless of their motive for getting involved in clinical trials, doctors should consider the time commitment involved.

It is useful to have family doctors recruit patients in order to get a general sample of the population, McDowell says. But she'd look "long and hard" at whether she could meet the requirement for trial involvement if she had a busy clinical practice.

In academic centres, doctors express frustration about issues such as the speed of research ethics board approval, resource management and contract arrangements, says Moody-Corbett.
Since it is "not in our interests to discourage researchers," her university has taken steps to streamline processes.

At the end of the day, most doctors really want to do the right thing for their patients, says Mamdani. "I think the money factor is important, but ... physicians have to feel this is an important issue they are dealing with clinically and buy into the trial. Otherwise, they are just doing it for money ... and I bet in those cases, recruitment rates aren't going to be that high." - Ann Silversides, CMAJ

DOI:10.1503/cmaj.090131
This article is part of a series on clinical trials that the CMAJ News section will run throughout 2009. Previous articles included an overview of the landscape of trials in Canada (CMAJ 2009;180[1]:20-22); a short history of trials (CMAJ 2009;180[1]:234); an article on the rising costs of trials (CMAJ 2009;180[3]:277-78); an article on drug development costs (CMAJ 2009;180[3]:279-80) and an article on recruiting patients (CMAJ 2009;180[4]: 375-8). Future articles will explore registration, ethical oversight, patient safety, reporting and the push for reforms.

\title{
Academy pitches new approach for evaluating research investments
}

W ith accountability having become the latest bureaucratic and political buzzword in Ottawa, research agencies are under increasing pressure to develop measures to ensure that tax dollars are spent wisely, while simultaneously demonstrating the value of a tax dollar invested in research, or in one specific discipline as opposed to another.

Are there more dividends in investing in home care research or directly in home care?

Is a tax dollar invested in health research more likely to yield economic and social dividends than a dollar invested in astronomy? Or even prove more costly to government coffers because research is a "cost-driver" of the health care system?

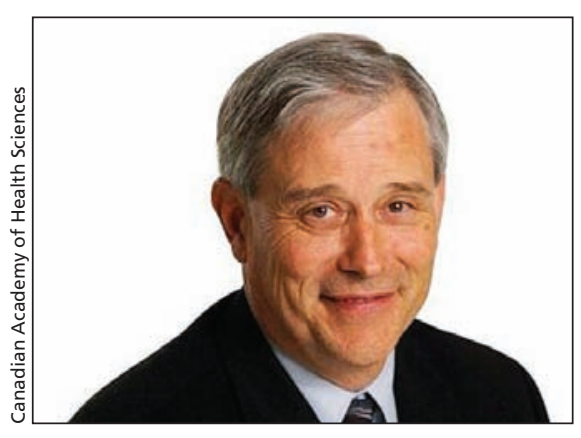

Canada could become an international leader in measuring the value of research investments, says Dr. Cyril Frank.
How should a department or agency determine priority areas of research investment?

The answers are as complex as the questions, the Canadian Academy of Health Sciences said while releasing the findings of its first major study since being founded in 2004 as a nonprofit organization providing independent advice to governments and interested parties. The $\$ 500000$ study was sponsored by 23 organizations.

The study's final report, Making an Impact: A Preferred Framework and Indicators to Measure Returns on Investment in Health Research, urges that governments, industry and national organizations adopt a new framework for evaluating and prioritizing research investments (www.cahs-acss.ca/e/pdfs /ROI_FullReport.pdf).

The framework uses a "systems approach" to measure return on investment and is based on a "payback model," developed by Martin Buxton and the Health Economics Research Group at Brunel University in the United Kingdom, under which research investments or programs are evaluated in 5 categories: "knowledge, benefits to future research, political and administrative benefits, health sector benefits, and broader economic benefits."

The framework was crafted by an international panel chaired by Dr. Cyril 
Frank, chief of the division of orthopaedics at the University of Calgary in Calgary, Alberta.

It essentially proposes a sort of pickand-choose approach in which decisionmakers select indicators (from a menu of 66) in response to their specific inquiries about the circumstances or types of projects that would yield the greatest return. Some of the indicators are quantitative. They range from citation impact and mortality rates to patient satisfaction, and even more subjectively, such concepts as "happiness" and "loneliness."

In essence, the framework could serve as a sort of aid to prioritization or a means of quantifying health outcomes relative to dollars invested. But arguably, it is so versatile that, depending on the indicators chosen, it could also be used to prove or disprove virtually any position. As a consequence, comparability between different evaluations could be problematic because of the built-in flexibility in the selection of indicators.

But Frank, Canadian Academy of Health Sciences President Dr. Martin Schechter, past-president Dr. Paul Armstrong and the report itself argue that the comparability problems and flexibility of the evaluation framework point to the need for health-research funders and decision-makers to begin collaborating on standardization of the nomenclature, methodologies, data collection and indicators.

"Canada should immediately initiate a national collaborative effort to begin to measure the impacts of Canadian health research," the report stated, proposing that government and other organizations fund the creation of a "national council to lead strategic planning and execution of the framework, with a formal secretariat and commissioned data collectors to begin this work."

Comparability could be a problem without a consensus on the methodologies and indicators by which return on investment should be measured, Frank told reporters at a Jan. 21 press conference. "If everybody picks different questions and different indicators, you would have a hodgepodge of potential answers." - Wayne Kondro, CMAJ

DOI:10.1503/cmaj.090174

\section{Federal listeriosis investigation has limited mandate}

$\mathrm{P}$ rime Minister Stephen Harper has appointed the former president of the Edmonton Health Authority to investigate last year's listeriosis outbreak, but she will not be able to subpoena witnesses or compel testimony.

Sheila Weatherill will report to Agriculture Minister Gerry Ritz by July 20 with recommendations of ways to avoid future outbreaks of food-borne disease, the Prime Minister's Office stated in in a press release.

But Weatherill - who will not be permitted to talk to reporters until the investigation is complete - will not make findings of criminal or civil liability, as her investigation lacks the scope or authority of a full-scale public inquiry.

The outbreak of listeriosis in August 2008, traced to contaminated processed meat from Maple Leaf Foods, killed 20 people. Maple Leaf Chief Executive Officer Michael McCain accepted responsibility and has since settled claims and compensated the families of those who died and the people who fell ill.

Critics say Harper hasn't give enough powers to find out whether Canada's food safety system failed during the outbreak.

As a consequence, Liberal Agricul- ture Critic Wayne Easter calls the investigation a "farce" because Weatherill can't examine the actions of the Canadian Food Inspection Agency and other levels of government - including the offices of the agriculture minister and the prime minister. Nor do victims and their families have a role and there's no guarantee the report will be made public, he adds.

Easter also says Weatherill is in conflict of interest as a member of the Prime Minister's Advisory Committee on the Public Service.

Dr. Kumanan Wilson, Canada Research Chair in Public Health at the University of Ottawa, says improvements in food safety, rather than optics, should have been the government's objective. Lacking authority to compel testimony, while being limited to reporting to the agriculture ministry rather than the Public Health Agency of Canada, the investigation is unlikely to address general food safety; the effectiveness of the disease surveillance system; or the efficacy of interdepartmental communications during an outbreak, he adds. - Laura Eggertson, CMAJ

\section{DOI:10.1503/cmaj.090165}

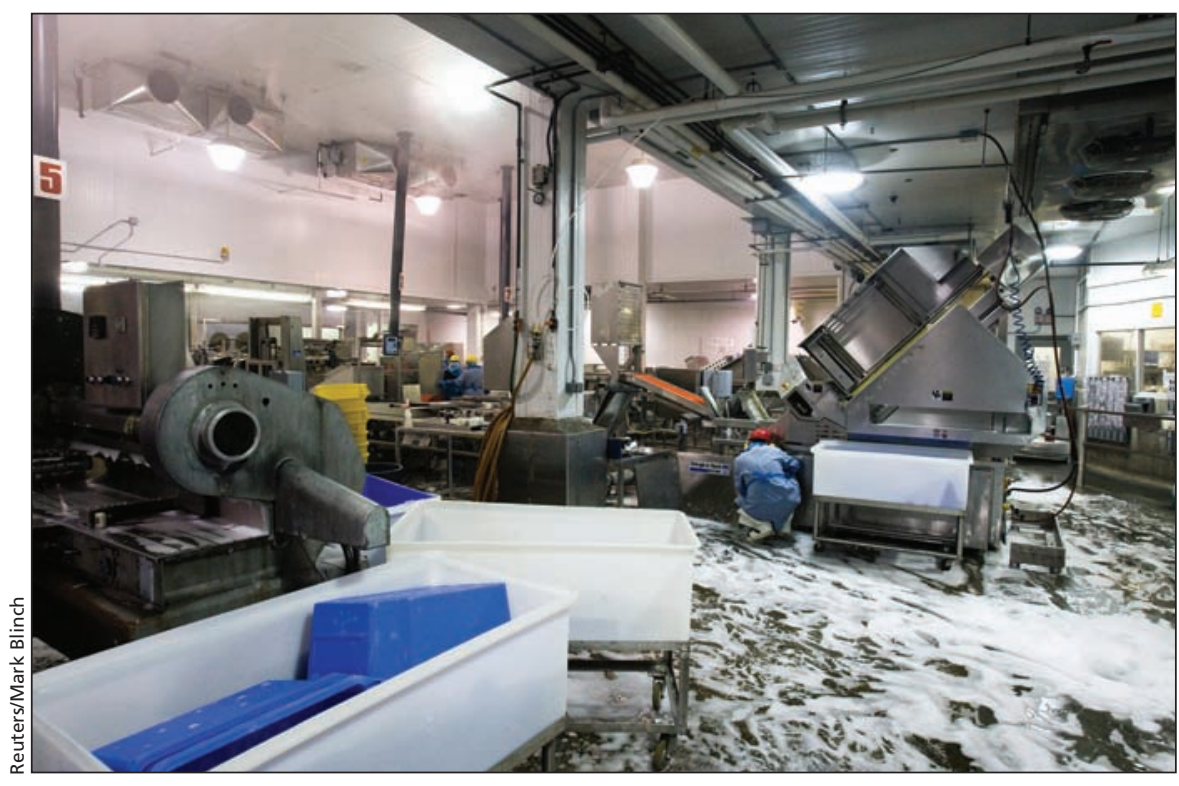

A man sterilizes meat and packaging equipment at the Maple Leaf Foods plant in Toronto, Ontario, site of the August 2008 outbreak of listeriosis that killed 20 people. 